\title{
LA EXPRESIÓN DE LA VOLUNTAD COMO EJERCICIO DEL DERECHO A LA AUTODETERMINACIÓN DE LAS PERSONAS, EN EL DOCUMENTO DE VOLUNTAD ANTICIPADA, DE ACUERDO A LA LEY DE VOLUNTAD ANTICIPADA PARA EL ESTADO DE GUANAJUATO EN MÉXICO
}

Gerardo Vicente Estrada Alvarado*

Recibido: 29.06 .2015

Aprobado: 11.08.2015

RESUMEN

El 3 de junio de 2011 fue publicada en el Periódico Oficial del Gobierno del Estado de Guanajuato, la Ley de Voluntad Anticipada para el Estado de Guanajuato, entrando en vigor el $1^{\circ}$ de enero de 2012;en esta, el Congreso del Estado de Guanajuato crea y norma el Documento de Voluntad Anticipada como expresión libre, inequívoca, consciente e informada a rechazar a priori tratamientos médicos futuros.

El 27 de diciembre del 2011 fue publicado en el mismo periódico oficial, el Reglamento de dicha Ley por parte del Gobernador del Estado de Guanajuato, entrando en vigor el cuarto día siguiente de su publicación; en este se establece la posibilidad de suspender los efectos del Documento de Voluntad Anticipada, permitiendo a terceros evitar temporalmente su cumplimiento; en el presente artículo, el autor analiza si se afecta con esto el derecho a la Autonomía de la persona humana.

\section{ABSTRACT}

On June 3rd, 2011, The Official Record of the Government of Guanajuato, published the Medical Advance Directive Law for the State of Guanajuato. Such law became effective on January 1, 2012. In this law, the Congress for the State of Guanajuato created and regulated the Medical Directive as a free, unequivocal, conscious and informed expression of an individual's refusal in advance, or future medical treatments.

On December 27, 2011, the same Official Record published the regulations for such law. Such regulations were to become effective on the fourth day after its publication. In these regulations there is established the possibility of suspending the effects of the Medical Advance Directive, allowing third parties to temporarily avoid their enforcement. In this article, the author discuss if this affect the right of autonomy of human beings.

\section{PALABRAS CLAVE}

Autonomía, Relación Médico Paciente, Enfermo Terminal, Consentimiento Informado, Acto Médico.

\section{KEY WORDS}

Autonomy, Physician-Patient Relationship, Terminal Illness, Informed Consent, Medical Act.

* Licenciado en Derecho por la Universidad Anahuac México Norte. Licenciado en Contaduría Pública por la Universidad del Centro del Bajio. Estudiante de la Maestría en Bioética de la Universidad Anáhuac México Norte. Coordinador Académico de la Escuela de Derecho de la Universidad Latina de México y Profesor Titular de las Cátedras de Derecho Mercantil I 


\section{INTRODUCCIÓN}

Legislar en materia de decisiones de salud de la persona humana, es consecuencia inmediata del legítimo interés que tiene la sociedad de protegerla, ya que su deterioro lleva a la terminación de la vida y durante este proceso el bienestar de las personas se ve mermado; por ello, ha sido prioridad social su investigación y, con ello, los efectos del desarrollo del conocimiento en nuevas tecnologías aplicadas a procedimientos médicos que permiten mantener con vida a enfermos en condición terminal, personas que antes hubiesen irremediablemente muerto en menor tiempo y ahora pueden ser mantenidas vivas por tiempos prolongados, no obstante su improbabilidad de curarse o de revertir sus condiciones de salud, pudiendo con ello ser sometidas indebidamente a prácticas de obstinación terapéutica por decisión médica y de familiares.

La Ley de Voluntad Anticipada para el Estado de Guanajuato, contiene además del Formato de Voluntad Anticipada, el Documento de Voluntad Anticipada, el cual será objeto de análisis en el presente, el cual como acto de libre expresión de voluntad revestido de legalidad, pretende hacer saber a priori a un potencial médico tratante, la autodeterminación del otorgante no necesariamente enfermo, a someterse o no a ciertos tratamientos médicos a futu- ro, cómo ser o no ser tratado medicamente de llegar a encontrarse diagnosticado como enfermo en situación terminal e impedido a decidir y expresar personalmente su decisión mediante el consentimiento informado, con las consecuencias que su decisión a priori ha consentido.

Prácticamente, este Documento de Voluntad Anticipada pretende suplir parcialmente a priori, el consentimiento informado que los familiares o representantes legales del paciente diagnosticado en situación terminal, tendrían que expresar al médico tratante en lo que hace a someterse o no a ciertos tratamientos terapéuticos, al estar impedido este a hacerlo personalmente, ahora en una situación real, presente e inmersos en circunstancias que rodean la vida del paciente y de sus familiares, estos últimos con ideas, emociones, intereses y circunstancias diferentes o similares a las del paciente, pero sometidos a un juicio de valor para la asunción de una responsabilidad que no es personal a su vida, sino a la de un tercero.

La voluntad se expresa en decisiones cotidianas del diario acontecer, como es elegir levantarse de la cama, qué alimento tomar o la ropa que vestir; en decisiones trascendentales eventuales, como vender una casa, elegir un gobernante, una pareja o tener hijos; estas son decisiones que por sus consecuencias se ven favorecidas generalmente por su regulación en leyes que pretenden el bienestar de quien decide y el bien común de los terceros relacionados con este, e incluso al discernir apoyamos la decisión en ocasiones con la guía y consejo de profesionales, la tomamos conscientes y libres, su alcance básicamente solo ocupa nuestra relación con las personas y los bienes en vida y no la vida misma; por ello, suscribir un Documento de Voluntad Anticipada, la distingo como una de las decisiones extraordinarias en la vida, pues sus consecuencias materiales tienen una relación directa con la dignidad, salud y la continuidad de nuestra vida biológica. Las circunstancias en las que una persona humana expresa su voluntad ante un Notario Público, son diferentes a las que tendrá al actualizarse el supuesto de aplicación efectiva del Documento de Voluntad Anticipada, ya que ahora sí existe un diagnóstico real, nace a la vida jurídica una relación médico-paciente, ha sido declarado enfermo en situación terminal, se encuentra inconsciente y no puede expresar su voluntad y por ello no puede consentir o no, someterse a ciertos tratamientos que pueden prolongarle su vida; esto lo convierte en una persona vulnerable, que requiere de una protección especial por parte del Estado en las leyes.

Todo lo anterior está plasmado básicamente en el artículo

(Sociedades), Derecho Mercantil II (Títulos y Operaciones de Crédito), Contratos Mercantiles y Derecho Fiscal II (Impuestos Federales y Locales). Corredor Público \# 3 en la Plaza del Estado de Guanajuato. Fungió como Presidente, Tesorero y Secretario del Colegio de Corredores Públicos del Estado de Guanajuato, de cuyo Consejo es actualmente el Secretario. Director de la firma Abogados y Asesores Empresariales, S.A. de C.V. 
primero de la Ley de Voluntad Anticipada para el Estado de Guanajuato que, a la letra, se lee como sigue:

"Artículo 1. La presente Ley es de orden público y tiene por objeto garantizar la atención médica a los enfermos en situación terminal, respetando su voluntad y dignidad humana."

El contenido de la Ley de Voluntad Anticipada para el Estado de Guanajuato, pretende garantizar una atención médica que respete la dignidad y la voluntad del paciente enfermo en situación terminal que no puede expresar la misma, lo que permite e impone su análisis bioético no solo como acto jurídico mismo de expresión de voluntad, sino especialmente de su cumplimiento y aplicación, partiendo de la base del respeto prioritario a su Dignidad, ya que, al estar inconsciente, se ve impedido a expresar su consentimiento libremente previa información del profesional médico que le atiende, para lo cual en ejercicio a su autonomía expresa a priori su voluntad, no obstante no encontrarse en tal situación, por lo que planteo la siguiente pregunta:

¿El Documento de Voluntad Anticipada es expresión de voluntad personal, libre, consciente, inequívoca e informada y con ello se respeta la voluntad y dignidad humana como lo establece la Ley de Voluntad Anticipada para el Estado de Guanajuato?

\section{Materiales y métodos}

Para dar contestación a la pregunta planteada y por ser un trabajo teórico básico que servirá como punto de partida para una posterior investigación que dé respuesta a las preguntas que surjan del estudio mismo, se lleva a cabo una investigación cuyo objetivo es descriptivo, con una amplitud micro por circunscribirse solo a una la Ley, por ello se desarrolla en un marco de campo y alcance seccional, con datos de naturaleza cualitativa, con datos secundarios y documental.

Se analizará la Ley de Voluntad Anticipada para el Estado de Guanajuato como objeto de estudio principal y necesariamente su Reglamento, al igual que la Ley General de Salud y el Reglamento de la Ley General de Salud en Materia de Prestación de Servicios de Atención Médica, aplicables en todo el territorio de los Estados Unidos Mexicanos, como punto de referencia comparativo general.

Todo lo anterior apoyado bibliográficamente en la parte teórica de literatura jurídica, filosófica y médica, para llegar a concluir la respuesta a la pregunta planteada y en su caso concluir si es menester proponer reformas a la Ley de Voluntad Anticipada para el Estado de Guanajuato.

\section{Desarrollo y discusión}

El Documento de Voluntad Anticipada se define en la Ley de Voluntad Anticipada para el Estado de Guanajuato como textualmente se cita a continuación:

"Artículo 4. Para efectos de esta Ley se entenderá por:
... III. Documento de voluntad anticipada: es el documento suscrito ante Notario, a través del cual toda persona con capacidad de ejercicio, en pleno uso de sus facultades mentales manifiesta su voluntad, libre, inequívoca, consciente e informada, a rechazar tratamientos médicos, que prolonguen su vida si llegare a encontrarse como enfermo en situación terminal; ..."

Esta expresión de voluntad deriva del ejercicio del derecho humano a la libertad de autodeterminación en la conducción de la vida del otorgante, que le permite anticipadamente elegir del universo infinito de sus ideas, qué hacer o dejar de hacer a su cuerpo cuando su estado de salud sea de considerarse el de un enfermo en situación terminal y estar en ese momento imposibilitado para expresar libremente su consentimiento informado para crear el vínculo de la relación médico paciente, además de evitar con ello dejar a terceros la responsabilidad para tomar este tipo de decisiones.

Proteger la dignidad de los seres humanos, especialmente en estas condiciones de vulnerabilidad, y garantizarles el respeto de su voluntad en todo momento, sobrepasa la sola idea de pretender disminuir el uso de los medios extraordinarios médicos existentes y evitar la obstinación terapéutica, así como evitar dejar la responsabilidad de decisión a familiares del enfermo terminal que no puede expresar su consentimiento o rechazo a lo que se le pretende hacer o no 
medicamente, evitando con ello conflictos entre los familiares dada la discrecionalidad y subjetividad en opiniones y decisiones relacionadas con el estado que presentan estos pacientes y de los tratamientos terapéuticos que les son aplicables en el momento.

Sin embargo, como todo tema derivado del ejercicio del libre albedrío de las personas humanas, evaluar la capacidad para decidir y poder considerar su voluntad anticipada como una elección informada, libre y reflexionada y no como simple liberalidad sin límites en el ámbito del derecho humano, requiere comprender el origen, estado, riesgos, beneficios y consecuencias de sus decisiones y tener el conocimiento informado suficiente para beneficiarse del respeto al ejercicio de su derecho a la autodeterminación como suscriptor del Documento de Voluntad Anticipada, el cual incidirá a posteriori en su relación médico paciente, la cual se pretende garantice una atención médica digna.

Con esta figura jurídica se pretende evitar el uso de medidas extraordinarias fútiles y evitar el encarnizamiento médico, así como evitar afectar a terceros al menos emocionalmente, en la toma de decisiones en relación a la salud del paciente terminal inconsciente, que generalmente recaen en los familiares de este e incluso puede recaer solo en la del médico responsable mismo cuando no hay representación legal alguna para la toma de decisiones y se sostiene como fundamento único el privilegio terapéutico que ejerce en su caso el médico tratante y lo pone en ocasiones en riesgo de responsabilidad civil o penal por el ejercicio profesional sin consentimiento informado.

Normar la libertad infiere que esta no sea absoluta, siendo especialmente relevante que el Estado lo haga en materia de salud, ya que ante todo debe proteger la vida de la persona humana, incluso por encima de la autodeterminación de las personas, ya que sin la vida como basamento o elemento natural para que existan los demás derechos, no habría más que proteger que tuviera relevancia a la existencia de dicha persona humana, la vida es requisito sine qua non para la de los demás derechos.

El Código Civil para el Estado de Guanajuato determina en su artículo 23, quien es capaz de expresar su voluntad anticipada:

"ARTÍCULO 23. El mayor de edad y el legalmente emancipado, tienen capacidad jurídica para disponer libremente de su persona $y$ de sus bienes, con las limitaciones que establece la ley."

Las consecuencias del ejercicio de la libertad pueden traer como consecuencias la incapacidad o final de la vida del paciente, las opciones a elegir van desde lo más general que es atenderse medicamente o no, hasta elegir al médico tratante, el hospital, el tratamiento, los medicamentos, los procedimientos, el costo de inversión o gasto, los cuidados; todo esto y más formará y permitirá expresar el consentimiento informado que representa el ejercicio de la autonomía del paciente, como derecho humano universal, inalienable e imprescriptible.

Tomando como primer punto de análisis del Documento de Voluntad Anticipada citado, el respeto de la voluntad del potencial enfermo terminal y dada la trascendencia de la consecuencia última que resultará fatal, distingo esta expresión de voluntad como una decisión extraordinaria, en un rango superior a las que denominé cotidianas y trascendentales, ya que la consecuencia de cumplirse su voluntad anticipada, es decir de dar cabalidad a su ejecución, resultará en algo que no puede ser sustituido, intercambiable, recuperable, llegado el final de la vida no hay marcha atrás, no hay recursos legales, médicos o mágicos para retrotraer sus efectos, o se está vivo o no.

Demandar la nulidad por ilegalidad de una voluntad anticipada que pretende evitar la utilización de medios extraordinarios que prolonguen la vida del paciente, asume poner en entredicho el alcance de la autonomía ejercida a priori por el paciente terminal, aun cuando este gozaba de cabalidad en la toma de decisiones, presume su incapacidad para expresarse libre y conscientemente, asume que su cumplimiento llevará a excluir lograr luchar por la vida, pretende evitar una locura que al parecer de otros, ya sean sus familiares o el propio personal médico, consideran una decisión equivocada y que atenta contra la protección y respeto de la vida misma. 
Las características de incurable e irreversible de la enfermedad del paciente en situación terminal, acompañada generalmente de dolores físicos que afectan la razón y alteran el equilibrio de las emociones, pueden poner en tela de juicio las decisiones del paciente; no obstante ello, la presencia del médico tratante en un diálogo efectivo, real, derivado de circunstancias presentes y particulares, que facilita al paciente una visión ampliada de su condición, las opciones, los riesgos, los beneficios, los costos y demás consecuencias propias del acto médico, permite al paciente discernir en mejor medida qué decisión tomar y sumar a su tratamiento curativo ya sea medidas ordinarias o de carácter extraordinario si así lo deseare.

Sin embargo, el buen juicio no se puede dar si el paciente terminal está inconsciente y se le ha pronosticado un plazo de vida no mayor a seis meses, por lo que sumar a esa condición su negativa a priori de recibir tratamientos que le prolonguen la vida, habiéndolo diagnosticado como enfermo terminal, impone que al prever poder verse impedido para expresarlo en ese momento y que esto recaería en la decisión de sus familiares o del personal médico, previó su voluntad anticipadamente y con ello sus consecuencias, por lo que debe el médico tratante cumplir su voluntad, salvo que el paciente recuperase plenamente su capacidad de ejercicio y cambiase de opinión.

La exposición de motivos de la iniciativa de la Ley obje- to de estudio, fechada 28 de octubre de 2010 y presentada por los diputados integrantes del grupo parlamentario del Partido Acción Nacional de la Sexagésima Primera Legislatura, plantea del debate bioético relacionado con el final de la vida humana el "derecho a morir con dignidad", sin sufrimiento y externa como finalidad para la aplicabilidad de la Voluntad Anticipada, los argumentos de proteger y garantizar la autodeterminación y la autonomía de la voluntad.

Adicionalmente, toma como punto de partida reconocer el derecho a la vida como fundamental y base de los demás derechos, aclara que no se pretende una eutanasia, la cual distingue de la ortotanasia que pretende respetar en todo momento la dignidad humana y la posibilidad de una calidad de vida mediante bienestar y alivio en el corto periodo que le resta al enfermo terminal, previendo una perspectiva ética de muerte digna mediante los cuidados paliativos que le eviten o reduzcan el dolor, lo hidraten y alimenten, así como ser atendido psicológica y espiritualmente.

Es relevante entender que respetar la autonomía de un paciente en la relación que el médico tiene con este, mediante el consentimiento informado, es el punto de partida en el que los derechos del primero y las obligaciones del segundo nacen e integran el vínculo más importante de una persona, pues son su salud y la vida los valores tutelados en este acuerdo, valores que forman parte inseparable del pacien- te, que es en consecuencia, además de sujeto contratante, objeto material del "contrato" $y$, en ánimo de no cosificarlo, se da preponderancia a su voluntad, previamente informada a detalle de los efectos de su decisión, para así respetar su dignidad como ser humano en todas sus dimensiones.

Lo anterior toma una especial relevancia cuando el paciente sufre una enfermedad que le clasifica como enfermo en situación terminal, ya que su vulnerabilidad no es solo física sino especialmente emocional, sabe que su situación es básicamente irreversible y mortal, por lo que le convierte en candidato a sufrir la obstinación médica o ser objeto de medios extraordinarios o fútiles, sensible en ocasiones además a dolores intensos y agravados con el tiempo, lo que hace que su calidad de vida, la que le reste, se evalúe en base a la posibilidad de aceptar continuar el proceso natural de terminación de su vida con una pretendida muerte digna o en una desafortunada eutanasia pasiva.

Entendida esta situación de vulnerabilidad del enfermo terminal, es que el legislador en Guanajuato incluyó en una ley el Documento de Voluntad Anticipada y el Formato de Voluntad Anticipada, mediante los cuales no solo pretende evitar la obstinación terapéutica, sino además abre como derecho a la protección de la salud del enfermo en situación terminal, el que pueda libremente optar por dejar o rechazar los procedimientos terapéuticos hospitalarios y retirarse al seno de su hogar 
para recibir los tratamientos paliativos que le acompañen, reduciendo el dolor y con los recursos al menos básicos al respeto de su dignidad como persona humana a la espera de la muerte.

A diferencia del Formato de Voluntad Anticipada que se materializa ante el personal de salud que atiende al paciente enfermo de situación terminal, lo que lleva a expresar el equivalente a un complemento del "consentimiento informado" por el propio paciente o por quienes la ley legitima al efecto, con el apoyo y asesoría del médico responsable o incluso orientados de opiniones médicas adicionales, con un diagnóstico real, particularizado, actualizado y la evaluación de circunstancias reales, el Documento de Voluntad Anticipada adolece de esto, ya que parte de un supuesto genérico probable de tratamientos potenciales y en consecuencia la decisión es a priori a la posible enfermedad que derivará en situación terminal y básicamente sin sustento o apoyo médico alguno.

La fracción v) del artículo 4 de la Ley en comento, refiere textualmente que el Formato de Voluntad anticipada:

“... es el documento suscrito por el enfermo en situación terminal, con capacidad de ejercicio, en pleno uso de sus facultades mentales, o por las personas legalmente facultadas para suscribirlo, ante el persona de la institución de salud que atiende al enfermo, a través del cual se manifiesta la voluntad, libre, inequívoca, consciente $e$ informada, a rechazar un determinado tratamiento médico, que prolongue de manera innecesaria y sin fines terapéuticos, la vida del enfermo;"

La propia Ley en comento establece para la expresión de la voluntad anticipada en sus dos opciones citadas, que debe ser libre, inequívoca, consciente e informada, diferenciando el objeto del consentimiento a rechazar un tratamiento médico específico en el caso del Formato, lo cual puede ser razonable pues se conoce la enfermedad y circunstancias específicas al que es aplicable y en el Documento abre a rechazar de manera genérica y plural tratamientos médicos, es obvio de que se trata de una mera especulación de situación terminal cuyas particularidades son desconocidas, aunque en ambos casos que refiere tratamientos que prolonguen la vida y no otros.

Esta generalidad de tratamientos a rechazar que permite determinarse por el suscriptor en el Documento de Voluntad anticipada, adolecen de aplicabilidad directa y consciente, ya que generaliza su aplicación al no correlacionarlos con enfermedad alguna, simplemente se rechazan, por lo que no puede tomar en cuenta otras circunstancias adicionales a la enfermedad pues la misma se desconoce al igual que se desconoce la institución de salud en la que vaya a ser atendido, el nivel de especialización del médico y su experiencia en tratar este tipo de enfermedad, los avances científicos médicos que pudieran apli- carse como medios ordinarios o extraordinarios y los medicamentos de más reciente creación, así como las demás particularidades no solo del entorno que rodea al paciente, sino la situación del propio paciente, tanto física, mental, emocional, económica como espiritualmente, junto con la gravedad, dolor, esperanza, riesgos y demás que en su caso influirían en la toma del consentimiento informado si estuviera consciente y actualizado al hecho del estado que guarde el enfermo en situación terminal y que se pretende a priori se hagan efectivos cuando sea diagnosticado así.

Adicionalmente, el legislador hace otra diferenciación que genera confusión de aplicabilidad en el fin del tratamiento, ya que en el Formato establece que este pretenda la prolongación de la vida del enfermo de manera innecesaria y sin fines terapéuticos, obviando que está en situación terminal, lo que sí hace en el Documento al referirlo específicamente, mas no distingue en este los tratamientos a rechazar, pudiendo entonces ser incluso los necesarios y terapéuticos, ya que solo refiere tratamientos médicos en general y en donde la ley no distingue no cabe distinguir; estaría entonces en la opción de rechazar cualquier tipo de tratamiento médico, incluso los que pudieran beneficiarle, por lo que la línea con la eutanasia pasiva sería muy frágil.

Una de las características del acto médico, es la subjetividad de su aplicación, ya que depende en gran medida de las decisiones que sugiere el 
médico responsable; no necesariamente a igual enfermedad se aplica un tratamiento terapéutico igual, ya que el libre ejercicio de la profesión médica, el constante avance de técnicas, procedimientos, equipos, medicamentos, materiales y demás elementos en que se apoya el actuar médico, variará, además de la medida en que un médico tenga más experiencia por conocimientos más especializados y más actualizados.

Lo anterior puede resultar poco importante para efecto del Documento en cuestión, sin embargo, cuando lo que se pretende evitar es la obstinación terapéutica, primero debemos definir dicho concepto, al igual que los correspondientes a medios ordinarios y extraordinarios, ya que de esto dependerá el alcance y límites entre los que se pretende regular el acto médico en relación a los enfermos en situación terminal, que a la vez es un concepto que debe incluirse dentro de estos parámetros y evitar con ello subjetividades. Sin embargo, la realidad es otra y precisamente termina siendo el perfil del acto médico como explico más adelante.

A efecto de determinar estos conceptos, la Ley de Voluntad Anticipada para el Estado de Guanajuato en su artículo 4 establece literalmente lo que debe entenderse por los conceptos referidos en el párrafo anterior, en diversos incisos como sigue:

"IV. Enfermo en situación terminal: es la persona que tiene una enfermedad incurable e irreversible y que tiene un pronóstico de vida inferior a seis meses."

Esta definición está afectada de subjetividad en el pronóstico de vida; es cierto que habrá particularidades de gravedad que permiten al médico detectar la cercanía e inmediatez de una muerte anunciada en periodos más cortos, pero pretender prolongarla hasta los seis meses resulta inútil, rebasar los seis meses o no llegar a ellos está fuera de control del diagnóstico médico.

En cuanto al diagnóstico de lo incurable o irreversible de una enfermedad, tendrá su fundamento en el conocimiento médico y en la experiencia de su propio ejercicio a nivel mundial, son determinantes y ciertas estas características, cuyo cambio dependerá del avance y novedad en la ciencia médica, en tanto no se dé el cambio seguirán siendo incurables e irreversibles.

Es responsabilidad del médico mantener con vida al paciente en situación terminal; sin embargo, su actuar debe limitarse a utilizar medios ordinarios y evitar los medios extraordinarios y los fútiles; para no caer en la obstinación terapéutica por su decisión o por la decisión de los familiares del paciente terminal, pudiera entenderse que basta que la norma de salud prohíba la obstinación terapéutica, pero no es así, ya que para determinar esta debemos saber en dónde termina el tratamiento terapéutico legal e inicia la obstinación.

En cuanto a los medios ordinarios y extraordinarios, así como la obstinación terapéutica, la misma Ley objeto de estudio los refiere en el artículo 4; no obstante, es ajena a definir los inútiles a menos que los considere sinónimos de extraordinarios, lo que se desprende de su lectura; analicemos uno por uno:

"X. Medios ordinarios: los que son útiles para conservar la vida del enfermo en situación terminal o para curarlo y que no constituyen para él, una carga grave o desproporcionada frente a los beneficios que se pueden obtener;"

Llevarlos a cabo tiene una razón básica, no obstante ser una carga esta no es grave, son útiles para conservar la vida del enfermo terminal, en tanto pueda durar la vida con estos medios, entendidos que se pronostica un periodo no mayor de seis meses contados a partir del diagnóstico de terminal; sin embargo, también refiere que sean útiles para curarlos, lo que se contrapone con su situación ya que supone es incurable, a menos que el legislador se refiera a otra u otras enfermedades que padezca el enfermo en situación terminal, pero que no sean la causa que le dio origen al diagnóstico que determine su situación como terminal, de otra manera no se entendería.

La utilidad del medio no debe ser una carga grave o desproporcionada, pero entonces ¿qué es una y qué es otra? Caemos de nuevo en la subjetividad al no establecerse el alcance conceptual legal, ¿qué hace que una carga sea grave simplemente y cuál que 
la carga sea desproporcionada?, en este caso el legislador distingue una de otra, es decir, la carga puede ser grave o desproporcionada, pero ello no las hace sinónimos y tampoco determina que pueden converger. No obstante que pretendiéramos interpretar el alcance de la carga comparando a contrario sensu estos medios con los extraordinarios, tampoco lo resolveríamos, baste para ello la lectura del párrafo siguiente, que más de aclarar considero que confunde más.

"IX. Medios extraordinarios: los que constituyen una carga demasiado grave para el enfermo y cuyo perjuicio es mayor que los beneficios; en cuyo caso, se podrán valorar estos medios en comparación al tipo de terapia, el grado de dificultad y de riesgo que comporta, los gastos necesarios y las posibilidades de aplicación respecto del resultado que se pueda esperar de todo ello;"

Tenemos ahora un tercer parámetro de gravedad de la carga. Primero, la carga carente de gravedad que se da en los medios ordinarios; segundo, una carga grave que desconocemos con qué tipo de medios se identifica, y este tercero como una carga que es demasiado grave; luego entonces, el acto médico con carga grave no está regulado, ya que de ausencia de gravedad se pasa directamente a demasiada gravedad, ¿cómo determino la gravedad y cómo la desproporción de la carga, cuando esta última ya no se establece como elemento de los medios extraordinarios?

Al parecer el legislador omitió incluir en el concepto de medios extraordinarios la característica de la carga desproporcionada, que a contrario sensu de los ordinarios debiera de incluirse, ya que se entiende no es sinónimo de demasiado grave; quiero, con ánimo de encontrar solución, entender que la frase "... cuyo perjuicio es mayor que los beneficios;" es precisamente la definición de "carga desproporcionada".

La técnica legislativa hubiese simplificado estas interpretaciones evitando el término "demasiado grave"; la carga en los medios ordinarios no debe ser grave; luego entonces, en medios extraordinarios es grave; de igual forma la carga no debe ser desproporcionada en los medios ordinarios, luego entonces serán extraordinarios cuando la carga sea desproporcionada y esta será desproporcionada cuando los perjuicios son mayores a los beneficios y esto se determinará tomando en cuenta la dificultad y riesgo del tipo de terapia, su costo y su aplicabilidad al resultado esperado.

No obstante lo anterior, seguiremos con el problema de interpretación que el médico responsable haga de estos, ya que la Ley en estudio en lugar de aclarar confunde, ya que suma estos conceptos de valor cuyo parámetro es de hecho y de derecho subjetivo y con ello discrecional al ejercicio de la profesión médica, ¿cómo mido ahora la dificultad y riesgo, el costo y la aplicabilidad atendiendo al resultado espe- rado? Solo el médico responsable lo sabrá.

Más que relevantes jurídicamente resultan estos conceptos, ya que son necesarios para determinar el siguiente concepto a definir y que precisamente es el más relevante, ya que la Ley objeto de estudio pretende evitarlo y es precisamente la obstinación terapéutica, concepto que a la letra establece este ordenamiento legal como:

"XI. Obstinación terapéutica: La adopción de medidas desproporcionadas o inútiles con el objeto de alargar la vida en situación de agonía;"

No es de sorprender el que este concepto sume confusión, ya que la obstinación terapéutica se basa en la desproporción, concepto que no quedó aclarado ni en los medios ordinarios ni extraordinarios, luego entonces ¿cuándo se da la desproporción? La única respuesta que se desprendería por deducción de la Ley en comento sería que, si los medios ordinarios son aquellos que son proporcionales, entonces todos los medios que no sean ordinarios pueden resultar en obstinación terapéutica, si tienen por objeto alargar la vida en situación de agonía.

¿Y cuándo se da la situación de agonía?

Ahora, como el legislador distingue, luego entonces cabe distinguir, entre la situación terminal y la situación de agonía, supongo refiriéndose al enfermo cuya vida se pretende alargar; sin embargo, de nueva cuenta el legislador confun- 
de con sus aclaraciones y por ello surge otra pregunta, ies la situación de agonía una etapa dentro de la misma situación terminal?, ¿es la misma o es diferente?

No considere el lector que aquí termina el calvario de aclaraciones, falta una más: el alcance de las medidas inútiles. La futilidad en el acto médico es un término reconocido, sin embargo la Ley en estudio lo omite a fin de distinguirlo o hacerlo sinónimo al de medidas desproporcionadas; de nuevo no pueden entenderse como sinónimos, ya que efectivamente puede haber medidas desproporcionadas a las circunstancias del caso pero útiles a la salud del paciente, puede haberlas desproporcionadas al beneficio en contraposición al perjuicio y resultar inútiles, sumando además que tengan por objeto prolongar la vida del enfermo en situación de agonía, término no definido por el legislador, lo que hace en consecuencia inaplicable su alcance legal en perjuicio directo del otorgante del Documento de Voluntad Anticipada.

Recordemos que tanto el Formato como el Documento de Voluntad Anticipada, pretenden básicamente rechazar tratamientos médicos que prolonguen la vida del enfermo en situación terminal y así evitar la obstinación terapéutica, pero si el concepto de esta última es erróneo, permitirá al médico tratante, llevar a cabo el acto médico de manera como mejor lo decida y hacer caso omiso si así lo desea de la expresión de autonomía del otorgante, quedando con ello violado el derecho humano de la autodeterminación.

Lo anterior demerita y obstaculiza la efectividad del Documento de Voluntad Anticipada, que como todo acto humano que se precie de ser una expresión de voluntad, debe ser personal, para ello debe ser libre, lo que impone una consciencia sustentada inequívocamente en lo que nos hemos informado, todo ello para que seamos responsables de las consecuencias del mismo al ejercer nuestro derecho a la libre autodeterminación como persona humana y es así como el legislador la pretende y establece sin mayor explicación. Sin embargo, amplía la problemática de la eficacia de su cumplimiento al ampliar el razonamiento aplicable para establecer las circunstancias que deben considerarse necesarias para poder legitimar el acto y evitar en la medida la nulidad del acto en su caso, es decir del Documento de Voluntad Anticipada.

El legislador establece en el artículo 22 de la Ley en estudio, que para la realización válida del Documento de Voluntad Anticipada y evitar su nulidad, no medien vicios del consentimiento, que este sea inequívoco en lo que expresa al responder las preguntas que le hace el Notario para cerciorarse de la identidad del solicitante, de la plenitud en su capacidad de ejercicio y de la forma en que expresa su voluntad al momento de suscripción del mismo, de otra forma la invalidez abriría la posibilidad de nulificar el acto, entendidos jurídicamente que la nulidad de un acto jurídico debe ser declarada por una autoridad judicial competente y no a consideración discrecional de particulares o de autoridades administrativas aún del sector salud.

La Ley de Voluntad Anticipada en comento, no refiere más en cuanto a la nulidad del acto de voluntades anticipadas, no obstante que las consecuencias de esta pueden afectar directamente uno de los postulados más importantes de la propia Ley desde su exposición de motivos, el respeto de la voluntad en base a la finalidad de proteger y garantizar la autodeterminación y la autonomía de la voluntad, protegidas tanto en el Formato como en el Documento de Voluntad Anticipada, el cual se otorga ante Notario pretendiendo dar el máximo de seguridad jurídica.

Como complemento y en forma supletoria a la Ley en estudio, el Código Civil para el Estado de Guanajuato, identifica los vicios del consentimiento, su alcance y sus consecuencias, con la simple lectura de los siguientes:

“ARTÍCULO 1282. El contratopuede serinvalidado: I. Por incapacidad legal de las partes o de una de ellas; II. Por vicios del consentimiento; III. Porque su objeto sea ilícito; IV. Porque el consentimiento no se haya manifestado en la forma que la ley establece.

... ARTíCULO 1300. El consentimiento no es válido si ha sido dado por error, 
arrancado por violencia u obtenido por dolo o mala fe.

\begin{abstract}
... ARTÍ́CULO 1301. El error de derecho no anula el contrato y el de hecho lo invalida cuando recae sobre el motivo determinante de la voluntad de cualquiera de los que contratan, si en el acto de la celebración se declara ese motivo o si se prueba por las circunstancias del mismo contrato que se celebró éste en el falso supuesto que lo motivó y no por otra causa."
\end{abstract}

... ARTíCULO 1719. La falta de forma establecida por la ley, si no se trata de actos solemnes, así como el error, el dolo, la violencia, la lesión y la incapacidad de cualquiera de los autores del acto, produce la nulidad relativa del mismo.

... ARTíCULO 1721. La nulidad por causa de error, lesión, dolo, violencia, o incapacidad sólo puede invocarse por el que ha sufrido esos vicios de consentimiento, o es el incapaz."

Sin embargo, no obstante que el Notario dé fe que la expresión de voluntad fue ante él libre, inequívoca, consciente e informada, es menester evaluar si efectivamente este profesional cuenta con elementos para considerar que la misma es informada y en consecuencia consciente, a fin de que no pueda ser afectada de vicios del consentimiento en la suscripción del Documento de Voluntad Anticipada.

Si bien la expresión de voluntad puede ser inequívoca por su contundencia en base al ejercicio de una libertad, esta puede no ser lo suficientemente responsable ya que está limitada por tratarse de dirigir a un acto médico no concreto, que requiere en todos los casos del conocimiento médico aplicable a una circunstancia determinada, el cual es limitado para el solicitante y el Notario por no ser peritos en la materia médica, a diferencia de la voluntad anticipada expresada mediante el Formato, ya que este lo consciente el suscriptor con el apoyo del personal de la institución de salud en la que se encuentra, es decir de peritos en la materia y aplicable a un caso en concreto.

Lo anterior hace vulnerable el consentimiento del otorgante del Documento de Voluntad Anticipada, ya que al no contar como requisito con la asesoría, orientación y explicación de un médico respecto del procedimiento o procedimientos terapéuticos que pretende rechazar a priori, sin estar necesariamente enfermo y establecida su situación terminal, la posibilidad de error se amplía y con ello la de nulificar sus efectos.

Entendidos que la Ley analizada no refiere más de la nulidad del acto, es menester referir lo que el Reglamento de la misma establece para la mejor aplicación de esta, siendo que en su artículo 12 establece literalmente:

"En caso de alguna controversia sobre la nulidad, validez y objeción familiar, médica o institucional, del documento de voluntad anticipada, formato de voluntad anticipada o del formato de revocación, se suspenderá el cumplimiento hasta que la autoridad competente resuelva."

Este precepto reglamentario, considero que no favorece el respeto a la autonomía del suscriptor del Documento de Voluntad Anticipada, ya que permite la objeción de los familiares, el personal médico, - la representación legal de las Instituciones de Salud, en clara violación al derecho humano de autodeterminación. Adicionalmente, no es constitucionalmente válido que un reglamento heterónomo vaya más allá que la propia Ley en el ámbito normativo, ya que su fin básico es proveer en la esfera administrativa la exacta observancia de la Ley de Voluntad Anticipada para el Estado de Guanajuato y no adicionar preceptos normativos autónomos a la referida Ley, como es el caso en comento.

Si el accionar legal procesal se lleva a cabo por los terceros referidos, el efecto de la suspensión preventiva del acto a que refiere el precepto reglamentario citado, es decir el Documento de Voluntad Anticipada, convierte nugatoria la eficacia de este y viola la autonomía de la voluntad establecida en la propia Constitución Política de los Estados Unidos Mexicanos, violando el derecho del enfermo en situación terminal, pues en tanto se resuelva en su caso la declaratoria de nulidad y atentos al pronóstico de vida inferior a seis meses, este seguramente requerirá ser mantenido vivo en forma artificial hasta que se resuelva la controversia, no 
habiendo procedimiento legal que ponga fin a la controversia en menos de seis meses y en consecuencia los motivos que dieron origen a la Ley son irremediablemente vulnerados a discreción que quienes ejerzan la acción correspondiente ante la autoridad competente.

Por otra parte, el reglamento en comento, agrega la objeción como herramienta jurídica para oponerse a la aplicación efectiva del Documento de Voluntad Anticipada, cuando la Ley en estudio no lo prevé, sumando a esto una inseguridad jurídica notoria en perjuicio del enfermo en situación terminal que a priori pretendió verse sometido a determinados procedimientos terapéuticos, lo que resultará ineficaz en tanto se resuelva la controversia, considero esto lo más grave y aberrante jurídicamente, ya que un precepto reglamentario de no más de tres renglones, elimina prácticamente el esfuerzo legislativo.

Otro de los problemas que puede generar este precepto reglamentario, es no especificar a qué se refiere como autoridad competente, ya que en un sentido estrictamente procesal la nulidad del Documento la debiera resolver un Juez, supongo en materia civil, sin embargo genera confusión ya que pudiera entenderse también dentro del ámbito de procuración de justicia a un agente del Ministerio Público o una autoridad de Salud.

El presente estudio es solo el inicio de una investigación que llevará necesariamente a proponer una reforma legislativa y reglamentaria que respete y haga eficaz el derecho humano a la autodeterminación en materia de tratamientos terapéuticos de los enfermos en situación terminal, pero para ello es menester enlistar la preguntas que se derivaron de la investigación, adicionales a las planteadas en el texto que antecede a las siguientes:

¿Existe en realidad una libre expresión de voluntad en decisiones genéricas anticipadas relacionadas a potenciales tratamientos médicos aplicables al enfermo en situación terminal?

Es fundamental que así como en el consentimiento informado se cubren requisitos de información indispensables que el médico provee al paciente para la libre expresión de voluntad, se cubra la libre expresión en el Documento de Voluntad Anticipada con la asesoría de un médico que ayude a construir una deliberación razonada, informada y con ello libre por parte del suscriptor de dicho documento.

¿Existe en realidad una libre expresión de voluntad en decisiones genéricas anticipadas relacionadas al universo de potenciales circunstancias que pudieran rodear al enfermo terminal?

Resultaría utópico considerar que el suscriptor del Documento de Voluntad Anticipada, conoce o pueda siquiera imaginar un listado de circunstancias que sean el motivo para rechazar determinados procedimientos terapéuticos o desde otro punto de vista, conocer todos los procedimientos terapéuticos que existen para prolongar la vida y rechazarlos de facto, cuando algunos de ellos pudieran salvarle permitir dar un paso adelante a otro procedimiento incluso, al que no se podrá llegar de haberse rechazado de facto el mismo de manera genérica.

¿Es posible reflexionar y tomar decisiones a priori que suplan un consentimiento informado como potencial enfermo terminal, sin conocer la enfermedad, tratamientos y medicamentos que le vayan a ser opción en el momento real?

Considero que no es posible hacerlo, ya que el universo de procedimientos $y$, más aún, el universo infinito de circunstancias y sus variables es tal, que generalizar sería de hecho un error del consentimiento, ya que no hay objeto real, es una toma de decisiones más allá de la aleatoriedad de las posibles enfermedades y circunstancias, independientemente del desarrollo continuo de nuevos procedimientos y medicamentos, pero no deja de ser importante dejar asentado cual es nuestro pensamiento al respecto y dar los elementos para que se tome la decisión más adecuada, estableciendo de facto lo que particularmente es rechazado como procedimiento médico en todos los casos, para evitar la obstinación terapéutica.

¿Es el Documento de Voluntad Anticipada para el Estado de Guanajuato un acto personalísimo que respeta la autonomía de un potencial paciente terminal? 
Sí es personalísimo, sin embargo dista de poder respetar la autonomía del suscriptor del Documento con la simple posibilidad de suspender temporalmente su aplicación en forma reglamentaria.

¿Es posible considerar el consentimiento expresado en un Documento de Voluntad Anticipada para el Estado de Guanajuato, afectado del error como vicio del consentimiento y en consecuencia factible suspender sus efectos por decisión de terceros en beneficio del otorgante?

La amplitud que puede darse al error en el consentimiento es tal que su apreciación no debiera ser objeto de litigio al haberlo otorgado ante un Notario Público; sin embargo, el mismo requerirá en todo caso cerciorarse como mejor considere, que el suscriptor del Documento de Voluntad Anticipada cuenta con la información médica suficiente para expresar su voluntad libremente, entendida esta libertad con responsabilidad, que a la vez impone la necesidad del conocimiento, de la capacidad de discernir por un razonamiento asesorado por un experto y con plena consciencia de sus efectos.

¿La posible actualización de un error del consentimiento expresado como se refiere en la pregunta anterior, impide cualquier gestión para hacer lo contrario por parte del personal médico, de sus familiares o de la representación social de autoridades competentes, cuya aplicación particular atenderá a circunstancias médicas específicas del momento real, que pueden tener resultados médicos diferentes que pudieran beneficiar al paciente prolongando su vida respetando su dignidad?

El respeto de la autonomía del paciente debe ser premisa del acto médico y con ello la delimitación del debido ejercicio de la profesión médica en un ámbito ya no paternalista como lo fue en antaño, sino ante todo de un debido respeto a la autodeterminación del enfermo en situación terminal, lo que no obsta para que el paciente reciba los cuidados básicos y paliativos en su caso, que le acompañen en esta etapa que llevará a la terminación de la vida en forma digna.

¿Tiene el Notario Público los conocimientos necesarios para asesorar y explicar los efectos de su decisión a la persona que acude ante él para expresar su voluntad y generar el instrumento legal que contenga el Documento de Voluntad Anticipada?

Considero que la asesoría legal del Notario Público le impone indirectamente la necesidad de sugerir al otorgante que reciba asesoría de un médico especializado en tratamientos para enfermos en situación terminal e incluso pida al suscriptor acompañe un certificado médico que exprese haber dado toda la información pertinente al caso particular.

¿Es lícito establecer reglamentariamente una acción que permita nulificar el Documento de Voluntad Anticipada, cuando el fin que pretende es que se respete su Voluntad y su Dignidad?
Considero que debe evitarse hacer esto, ya que para ello existen las normas adjetivas pertinentes, no obstante pudiera aclararse en forma específica a qué se refiere con autoridad competente y establecer plazos y términos para evitar que la suspensión haga ineficaz el respeto al cumplimiento del Documento de referencia.

¿Es el Documento de Voluntad Anticipada una expresión anticipada equiparable o sustituta del Consentimiento Informado en la relación Médico Paciente?

Considero que es complementaria al Consentimiento Informado y que debe formar parte del mismo, dentro del expediente médico del paciente considerado enfermo en situación terminal en todos los casos, ya como Documento de haberlo o como Formato cuando se actualice el supuesto de ser considerado en ese estado.

\section{Conclusiones de propuesta} LEGISLATIVA Y REGLAMENTARIA

1) La expresión de voluntad en el Documento de Voluntad Anticipada otorgado ante un Notario Público de acuerdo a la Ley de Voluntad Anticipada para el Estado de Guanajuato, puede ser atacada de nulidad por terceros y lograr con ello impedir su cumplimiento discrecionalmente en tanto se resuelve la declaración de nulidad, toda vez que el Reglamento de la Ley establece la suspensión temporal de sus efectos en tanto se resuelva la controversia planteada, 
por lo que debe derogarse el precepto reglamentario que así lo establece.

2) Toda vez que el Reglamento de la Ley no plantea un procedimiento legal expedito menor a la naturaleza de las enfermedades en situación terminal, el enfermo se verá irremediablemente sujeto a procedimientos terapéuticos que lo mantengan con vida hasta en tanto se ponga fin a la controversia, además de derogarse el precepto reglamentario, debe agregarse el procedimiento expedito en la propia Ley y solo como acción ejercitable por quien haya sido designado representante legal de la voluntad anticipada del suscriptor del propio Documento, sujeto considerado en el ordenamiento legal y que será designado en el mismo Documento por el suscriptor.

3) El Documento de Voluntad Anticipada adolece de la certeza jurídica de que el mismo sea resultado de la expresión del consentimiento consciente $e$ informado, si no cuenta con la asesoría y apoyo en su construcción de un médico especializado en enfermos en situación terminal, que le permita suponer los hechos futuros inciertos que pudieran ser aplicables a su voluntad de someterse o no a determinados tratamientos terapéuticos, por lo que deberá agregarse como requisito contar con un Certificado que afirme haber dado la información necesaria al suscriptor.
4) Se sugiere llevar a cabo las reformas y adiciones necesarias a la Ley de Voluntad Anticipada para el Estado de Guanajuato y su Reglamento, que permitan asegurar a las personas el cumplimiento de su voluntad anticipada, en caso de ser diagnosticadas como enfermos en situación terminal y verse impedidos a expresar su voluntad, para lo cual deberá establecerse de manera determinante, los conceptos de Obstinación Terapéutica, Medidas Extraordinarias y Ordinarias, Elemento de Proporcionalidad y Desproporcionalidad, así como evitar conceptos que confundan los así establecidos, evitar los sinónimos y establecer claramente que la objeción de consciencia médica solo consistirá en el derecho del médico a no cumplir personalmente con el Documento de Voluntad Anticipada, evitando llevar a cabo actos $u$ omisiones que hagan irreparable su negativa, debiendo proceder de inmediato a poner en manos de otro médico el cumplimiento del contenido del Documento y dar prioridad al respeto de la Autonomía del paciente, evitando la Obstinación Terapéutica.

\section{REFERENCIAS BIBLIOGRÁFICAS}

Baqueiro, E. (1997). Violencia. En: Diccionarios jurídicos temáticos, Derecho Civil (Vol.1).México:Harla.

Bonnecase, J. (1997). Tratado elemental de derecho civil (Vol.1) (E. Figueroa, Trad.). México:Harla.
Bruger, W. (1988). Diccionario de Filosofía.Barcelona: Editorial Herder.

Bustos, M.B. (2003). Capacidad, en Diccionarios Jurídicos temáticos, Personas y Familia (Vol.1).México: Oxford.

Constitución Política de los Estados Unidos Mexicanos, disponible en http://www. diputados.gob.mx, consultado en junio 2015.

Constitución Política para el Estado de Guanajuato, disponible en http://www. congresogto.gob.mx, consultado en junio 2015.

Documento de Voluntad Anticipada. (2014). Colegio de Notarios del Distrito Federal, disponible en http://www. colegionotarios.org.mx, consultado en junio 2015.

Espejo, M.D. (2006). Voluntades Anticipadas, en Diccionario de Bioética, Simón, C. España: Editorial Monte Carmelo.

Espejo, M.S. y Vega, J. (2006). Eutanasia, en Diccionario de Bioética, Simón, C. España: Editorial Monte Carmelo.

Gevaert, J. (1995). El problema del hombre. Introducción a la Antropología Filosófica, $10^{a}$ edición. España: Ediciones Sígueme.

Inicia "marzo mes de la voluntad anticipada". (2014). Colegio de Notarios del Distrito Federal, disponible en http: / / www.colegiodenotarios.org.mx, consultado en junio 2015. 
Kubler, E. (1999). La muerte: un amanecer. (Jáuregui, P. Trad.). España: Luciérnaga.

Laurent, A. (2013). Consentimiento Informado y Daño Moral. En Marín, J.C., Moctezuma, G., Ramírez, A., Salgado, E., Silva, M.E. Error Médico y Daño Moral. México: Porrúa.

Ley de Voluntad Anticipada para el Estado de Guanajuato, disponible en http: / / www.congresogto.gob.mx, consultado en junio 2015.

Ley del Notariado para el Estado de Guanajuato, disponible en http://www.congresogto.gob.mx, consultado en junio 2015.

Ley General de Salud, disponible en http://www.diputados.gob.mx, consultado en junio 2015.

Lineamientos para la aplicación de la Ley de Voluntad Anticipada para el Estado de Guanajuato, así como los Formatos de Voluntad Anticipada y de Revocación de Voluntad Anticipada, emitidos por el Secretario de Salud del Estado, disponible en http://www.congresogto.gob.mx, consultado en junio 2015.

Nino, C.S. (1094). Ética y Derechos Humanos. Buenos Aires: Paidós.

Obligio, O. (1998). Principios de Bioética, Pontificia Universidad Católica Argentina.Buenos Aires: Fundación Alberto Roemmers.

Pérez, J.J. (2006). Acto Médico, en Diccionario de Bioética, Simón, C. España: Editorial Monte Carmelo.

Poisson, J.F. (2009). Bioética ¿El hombre con el hombre?. Madrid: Ediciones Rialp.

Reglamento de la Ley de Voluntad Anticipada para el Estado de Guanajuato, dis- ponible en http://www. congresogto.gob.mx, consultado en junio 2015.

Reglamento de la Ley General de Salud en materia de prestación de servicios de atención médica, disponible en http: / / www. diputados.gob. mx, consultado en junio 2015.

Reich, W. (1982). Encyclopedia of Bioethics.Georgetown University, USA: The Free Press.

Tomás, M.C. y Tomás, G. (2006). Valores, en Diccionario de Bioética, Simón, C. España: Editorial Monte Carmelo.

Varga, A. (1988). Bioética Principales Problemas, (Llano, A. Trad.).Bogotá: Ediciones Paulinas. 